\title{
Educação Popular: de uma Prática Alternativa a uma Estratégia de Gestão Participativa das Políticas de Saúde
}

EYMARD MOURÃO VASCONCELOS

A aproximação de muitos profissionais de saúde com o movimento da Educação Popular e a luta dos movimentos sociais pela transformação da atenção à saúde possibilitaram a incorporação, em muitos serviços de saúde, de formas de relação com a população bastante participativas e que rompem com a tradição autoritária dominante. Contribuíram muito na desconstrução do autoritarismo dos doutores, do desprezo ao saber e à iniciativa dos doentes e familiares, da imposição de soluções técnicas para problemas sociais globais e da propaganda política embutida na forma como o modelo biomédico vem sendo implementado. No entanto, não basta alguns saberem fazer. É preciso que esse saber seja difundido e generalizado nas instituições de saúde. O avanço da força dos grupos políticos ligados aos movimentos sociais do Brasil vem criando condições institucionais para superar a fase em que essas práticas de saúde mais integradas à lógica de vida da população aconteciam apenas em experiências alternativas pontuais e transitórias. É preciso encontrar os caminhos administrativos e de formação profissional que permitam sua generalização no SUS.

Palavras-chave: Educação Popular; movimentos sociais; práticas de saúde. 
Chega de fazer para os empobrecidos. Chegou a hora de fazer a partir deles e com eles. Essa é a novidade que você traz na esteira de Paulo Freire e da Igreja da libertação.

Leonardo Boff, em carta aberta ao Presidente Lula, após sua eleição.

\section{Introdução}

A educação em saúde é o campo de prática e conhecimento do setor saúde que tem se ocupado mais diretamente com a criação de vínculos entre a ação médica e o pensar e fazer cotidiano da população. Diferentes concepções e práticas têm marcado a história da educação em saúde no Brasil. Mas, até a década de 1970, a educação em saúde no Brasil foi basicamente uma iniciativa das elites políticas e econômicas e, portanto, subordinada aos seus interesses. Voltava-se para a imposição de normas e comportamentos por elas considerados adequados.

\section{A Aproximação do Setor Saúde com o Movimento da Educação Popular}

O governo militar, imposto pela Revolução de 1964, criou contraditoriamente condições para a emergência de uma série de experiências de educação em saúde que significaram uma ruptura com o padrão acima descrito. Nessa época, a política de saúde se voltou para a expansão de serviços médicos privados, principalmente hospitais, onde as ações educativas não tinham espaço significativo. A "tranqüilidade" social imposta pela repressão política e militar permitindo que o regime voltasse suas atenções para a expansão da economia, diminuindo os gastos com as políticas sociais. Com os partidos e sindicatos esvaziados, a população foi aos poucos buscando novas formas de resistência. A Igreja Católica, que conseguira se preservar da repressão política, apoiou esse movimento, possibilitando o engajamento de intelectuais das mais diversas áreas. O método da Educação Popular, sistematizado por Paulo Freire, se constituiu como norteador da relação entre intelectuais e classes populares. Muitos profissionais de saúde, insatisfeitos com as práticas mercantilizadas e rotinizadas dos serviços de saúde, se engajaram nesse processo. Nos subterrâneos da vida política e institucional, foi-se tecendo a estrutura de novas 
formas de organização da vida política. Tais experiências possibilitaram (e ainda possibilitam) que intelectuais tenham acesso e comecem a conhecer a dinâmica de luta e resistência das classes populares. No vazio do descaso do Estado com os problemas populares, vão se configurando iniciativas de busca de soluções técnicas construídas a partir do diálogo entre o saber popular e o saber acadêmico.

O setor saúde é exemplar nesse processo. Nos anos 70, junto aos movimentos sociais emergentes, começaram a surgir experiências de serviços comunitários de saúde desvinculados do Estado, em que profissionais de saúde aprendiam a se relacionar com os grupos populares, começando a esboçar tentativas de organização de ações de saúde integradas à dinâmica social local. Com o processo de abertura política, movimentos populares, que já tinham avançado na discussão das questões de saúde, passaram a reivindicar serviços públicos locais e a exigir participação no controle de serviços já estruturados.

A experiência ocorrida na Zona Leste da cidade de São Paulo é o exemplo mais conhecido, mas o Movimento Popular de Saúde (MOPS) chegou a aglutinar centenas de outras experiências nos diversos estados. Nelas a educação em saúde buscou ser uma assessoria técnica e política às demandas e iniciativas populares, bem como um instrumento de dinamização das trocas de conhecimento entre os atores envolvidos. Assim, a participação de profissionais de saúde nas experiências de Educação Popular, a partir dos anos 70 , trouxe para o setor saúde uma cultura de relação com as classes populares que representou uma ruptura com a tradição autoritária e normatizadora da educação em saúde.

Com a conquista da democracia política e a construção do Sistema Único de Saúde, na década de 1980, essas experiências localizadas de trabalho comunitário em saúde perderam sua importância. Os movimentos sociais passaram a lutar por mudanças mais globais nas políticas sociais. Os técnicos que nelas estiveram engajados agora ocupam espaços institucionais amplos, onde uma convivência direta tão intensa com a população não é mais possível. Mas a experiência de integração vivida por tantos intelectuais e líderes populares, o saber ali construído e os modelos institucionais que começaram a ser gestados continuam presentes.

Em muitas instituições de saúde, grupos de profissionais têm buscado enfrentar o desafio de incorporar no serviço público a metodologia da Educação 
Popular, adaptando-a ao novo contexto de complexidade institucional e da vida social nos grandes centros urbanos. Enfrentam tanto a lógica hegemônica de funcionamento dos serviços de saúde, subordinados aos interesses de legitimação do poder político e econômico dominante, como a carência de recursos oriunda do conflito distributivo no orçamento, numa conjuntura de crise fiscal do Estado. Neste sentido, esses grupos estão engajados na luta pela democratização do Estado, na qual o método da Educação Popular passa a ser um instrumento para a construção e ampliação da participação popular no gerenciamento e reorientação das políticas públicas.

Atualmente há duas grandes interfaces de relação educativa entre os serviços de saúde e a população: os grandes meios de comunicação de massa e a convivência cotidiana dos profissionais com a população nos serviços de saúde. A segunda interface, na medida em que permite um contato muito próximo entre os vários atores envolvidos no processo educativo, permite um rico aprendizado dos caminhos de uma educação em saúde que respeite a autonomia e valorize a criatividade dos educandos. Neste sentido, os conhecimentos construídos nessas experiências mais localizadas são fundamentais para o norteamento das práticas educativas nos grandes meios de comunicação de massa, se o objetivo é uma metodologia participativa. É preciso superar a atual situação, em que as grandes campanhas educativas em saúde são organizadas por grandes empresas de comunicação muito pouco articuladas com o cotidiano de relação entre os profissionais de saúde e a população.

\section{Educação Popular, um Jeito Especial de Conduzir o Processo Educativo}

No nível internacional, o Brasil teve papel pioneiro na constituição do método da Educação Popular, o que explica em parte a sua importância, aqui, na redefinição de práticas sociais dos mais variados campos do saber. Ela começou a se estruturar como corpo teórico e prática social no final da década de 1950, quando intelectuais e educadores ligados à Igreja Católica e influenciados pelo humanismo personalista que florescia na Europa no pósguerra se voltaram para as questões populares. Paulo Freire foi o pioneiro no trabalho de sistematização teórica da Educação Popular. Seu livro Pedagogia do oprimido (1966) ainda repercute em todo o mundo. 
Educação Popular não é o mesmo que "educação informal”. Há muitas propostas educativas que se dão fora da escola, mas que utilizam métodos verticais de relação educador-educando. Segundo Carlos Brandão (1982), a Educação Popular não visa a criar sujeitos subalternos educados: sujeitos limpos, polidos, alfabetizados, bebendo água fervida, comendo farinha de soja e utilizando fossas sépticas. Visa a participar do esforço que já fazem hoje as categorias de sujeitos subalternos - do índio ao operário do ABC Paulista - para a organização do trabalho político que, passo a passo, abra caminho para a conquista de sua liberdade e de seus direitos. A Educação Popular é um modo de participação de agentes eruditos (professores, padres, cientistas sociais, profissionais de saúde e outros) nesse trabalho político. Ela busca trabalhar pedagogicamente o homem e os grupos envolvidos no processo de participação popular, fomentando formas coletivas de aprendizado e investigação, de modo a promover o crescimento da capacidade de análise crítica sobre a realidade e o aperfeiçoamento das estratégias de luta e enfrentamento. É uma estratégia de construção da participação popular no redirecionamento da vida social.

Um elemento fundamental do seu método é o fato de tomar, como ponto de partida do processo pedagógico, o saber anterior do educando. No trabalho, na vida social e na luta pela sobrevivência e pela transformação da realidade, as pessoas vão adquirindo entendimento sobre a sua inserção na sociedade e na natureza. Esse conhecimento fragmentado e pouco elaborado é a matéria-prima da Educação Popular. A valorização do saber e valores do educando permitem que ele se sinta "em casa" e mantenha sua iniciativa. Neste sentido, não se reproduz a passividade usual dos processos pedagógicos tradicionais. Na Educação Popular, não basta que o conteúdo discutido seja revolucionário se o processo de discussão se mantém de cima para baixo. Enfatiza não o processo de transmissão de conhecimento, mas a ampliação dos espaços de interação cultural e negociação entre os diversos atores envolvidos em determinado problema social, para a construção compartilhada do conhecimento e da organização política necessários à sua superação. Ao invés de procurar difundir conceitos e comportamentos considerados corretos, procura problematizar, em uma discussão aberta, o que está incomodando e oprimindo. Prioriza a relação com os movimentos sociais por serem expressão mais elaborada dos interesses e da lógica dos setores subalternos da sociedade, cuja voz é usualmente desqualificada nos diálogos e negociações. Apesar de, muitas vezes, partir da busca de soluções para problemas específicos e localizados, o faz a partir da perspectiva de que a atuação na microcapilaridade 
da vida social é uma estratégia de desfazer os mecanismos de cumplicidade, apoio e aliança, os micropoderes, que sustentam as grandes estruturas de dominação política e econômica da sociedade. Está, pois, engajada na construção política da superação da subordinação, exclusão e opressão que marcam a vida na nossa sociedade.

Educação Popular é o saber que orienta nos difíceis caminhos, cheios de armadilhas, da ação pedagógica voltada para a apuração do sentir/pensar/ agir dos setores subalternos para a construção de uma sociedade fundada na solidariedade, justiça e participação de todos.

\section{De uma Prática Alternativa a uma Estratégia de Reorientação da Política de Saúde}

Passados quarenta anos do início desse movimento no Brasil, muita coisa mudou. As práticas de Educação Popular em saúde já não se restringem ao modelo dominante na década de setenta: um técnico inserido numa pequena comunidade periférica, identificando lideranças e problemas mobilizadores, criando espaços de debate, apoiando as lutas emergentes e trazendo subsídios teóricos para alargar as discussões locais. Com o processo de democratização da sociedade brasileira, houve espaço para que a participação popular pudesse também ocorrer nas grandes instituições.

Muitos técnicos formados nos espaços informais dos movimentos sociais passaram a ocupar cargos importantes nos órgãos implementadores das políticas de saúde, procurando aplicar, nesse novo espaço, a metodologia da Educação Popular. Apesar de uma certa crise inicial da pretensão de transposição direta e sem adaptações da metodologia de ação nos espaços informais para as instituições, novas experiências floresceram. A Rede de Educação Popular e Saúde, que, desde 1991, articula profissionais de saúde e lideranças populares envolvidas nessas experiências, vem se expandindo e consolidando a trajetória de atuação nos novos serviços de saúde a partir do instrumental da Educação Popular.

Pode-se afirmar que grande parte das experiências de Educação Popular em Saúde está hoje voltada para a superação do fosso cultural existente entre os serviços de saúde, as organizações não-governamentais, o saber médico e mesmo as entidades representativas dos movimentos sociais, de um lado, e, 
de outro, a dinâmica de adoecimento e de cura do mundo popular. Isto é feito a partir de uma perspectiva de compromisso com os interesses políticos das classes populares, mas reconhecendo, cada vez mais, sua diversidade e heterogeneidade. Atuando a partir de problemas de saúde específicos ou de questões ligadas ao funcionamento global dos serviços, busca-se entender, sistematizar e difundir a lógica, o conhecimento e os princípios que regem a subjetividade dos vários atores envolvidos, de forma a superar incompreensões e mal-entendidos ou tornar conscientes e explícitos os conflitos de interesse. Dedica-se à ampliação dos canais de interação cultural e negociações (cartilhas, jornais, assembléias, reuniões, cursos, visitas etc.) entre os diversos grupos populares e os diversos tipos de profissionais e instituições.

A partir desse diálogo, soluções vão sendo delineadas. Neste sentido, a Educação Popular tem significado não uma atividade a mais que se realiza nos serviços de saúde, mas uma ação que reorienta a globalidade das práticas ali executadas, contribuindo na superação do biologicismo, autoritarismo do doutor, desprezo pelas iniciativas do doente e seus familiares e da imposição de soluções técnicas restritas para problemas sociais globais que dominam a medicina atual. É, assim, um instrumento de construção da ação de saúde mais integral e mais adequada à vida da população.

A Educação Popular não é o único projeto pedagógico a valorizar a diversidade e heterogeneidade dos grupos sociais, a intercomunicação entre diferentes atores, o compromisso com as classes subalternas, as iniciativas dos educandos e o diálogo entre o saber popular e o saber científico. Mas, para o setor saúde brasileiro, a participação histórica no movimento da Educação Popular foi marcante na criação de um movimento de profissionais que busca romper com a tradição autoritária e normatizadora da relação entre os serviços de saúde e a população. Apesar de uma certa crise do conceito da Educação Popular nos novos tempos, é ele que vem servindo para identificar e instrumentalizar a diversidade de práticas emergentes. Nessas experiências, os vários aspectos metodológicos valorizados articulam-se de modo peculiar, diferenciando-se do que ocorre em outros continentes. Há um elemento inovador e pioneiro nas experiências brasileiras e latino-americanas de Educação Popular em Saúde, que vem sendo reconhecido internacionalmente.

Para muitos serviços de saúde, a Educação Popular tem significado um instrumento fundamental na construção histórica de uma medicina integral, na medida em que se dedica à ampliação da inter-relação entre as diversas 
profissões, especialidades, serviços, doentes, familiares, vizinhos e organizações sociais locais envolvidos num problema específico de saúde, fortalecendo e reorientando suas práticas, saberes e lutas. A redefinição da prática médica se dá não a partir de uma nova tecnologia ou um novo sistema de conhecimento, como as chamadas medicinas alternativas pretendem ser, mas pela articulação de múltiplas, diferentes e até contraditórias iniciativas presentes em cada problema de saúde, em um processo que valoriza principalmente os saberes e práticas dos sujeitos usualmente desconsiderados devido a sua origem popular.

No atual contexto de fragmentação da vida social, a recomposição de uma abordagem mais globalizante da saúde não pode caber apenas às iniciativas ampliadas das instituições médicas. Tal recomposição da integralidade nas práticas de saúde cabe principalmente ao crescimento da capacidade de doentes, famílias, movimentos sociais e outros setores da sociedade civil para articular, usufruir e reorientar os diversos serviços e saberes disponíveis segundo suas necessidades e realidades concretas. Esta perspectiva se diferencia do imaginário de grande parte do movimento sanitário brasileiro, ainda acreditando e se empenhando na possibilidade de construção de um sistema estatal único de saúde capaz de penetrar e ordenar, de modo organizado, as diversas instâncias da vida social implicadas no processo de adoecimento e de cura (Vasconcelos, 1997).

Desde o início dos anos noventa, profissionais de saúde envolvidos em práticas de Educação Popular organizaram a Rede de Educação Popular e Saúde ${ }^{2}$, com o intuito de fortalecer o debate sobre as relações educativas nos serviços de saúde. Desde então, assistimos a uma importante organização institucional do campo da Educação em Saúde. Estruturaram-se encontros em vários estados; vários congressos de âmbito nacional dedicaram significativos espaços ao tema; criaram-se grupos acadêmicos e operativos e aumentaram as publicações. Mas é ainda uma estruturação muito frágil, se temos em vista o grande número de profissionais de saúde que se preocupam com relações educativas com a população e a elas se dedicam.

\section{A Construção de uma Política de Educação Popular para o SUS}

A Rede de Educação Popular e Saúde, articulando e acompanhando centenas de experiências de aprofundamento da participação popular nos serviços de saúde, acredita que a Educação Popular continua sendo um 
instrumento metodológico fundamental para uma reorganização mais radical do SUS, no sentido da construção de uma atenção à saúde integral em que as pessoas e os grupos sociais assumam maior controle sobre sua saúde e suas vidas, e em que a racionalidade do modelo biomédico dominante seja transformada no cotidiano de suas práticas. Nesse sentido, a Educação Popular não é mais uma atividade a ser implementada nos serviços, mas uma estratégia de reorientação da totalidade das práticas ali executadas, na medida em que investe na ampliação da participação que, dinamizada, passa a questionar e reorientar tudo (Rede de Educação Popular e Saúde, 2003).

O princípio da participação popular costuma ser aceito e defendido por todos; contudo, tende-se a acreditar que tal princípio se opera quase espontaneamente, uma vez assegurados legalmente os espaços formais de sua implementação: a saber, os conselhos e as conferências de saúde. Constatase, no entanto, que essas instâncias, por estarem presas às questões gerenciais do sistema, não dão conta de implementar a participação dos usuários na redefinição da maioria das ações de saúde executadas no dia-a-dia dos serviços. Há inúmeros mecanismos de boicote a uma participação mais efetiva dos moradores. E é no cotidiano das práticas de saúde que o cidadão é desconsiderado, pelo autoritarismo e pela prepotência do modelo biomédico tradicional que, ao invés de questionar, tem reforçado as estruturas geradoras de doença presentes na forma como a vida hoje se organiza. É preciso levar a democratização da assistência à microcapilaridade da operacionalização dos serviços de saúde. Sem a participação ativa dos usuários e seus movimentos na discussão de cada conduta ali implementada, os novos serviços expandidos não conseguirão se tornar um espaço de redefinição da vida social e individual em direção a uma saúde integral.

A Rede de Educação Popular e Saúde tem acompanhado centenas de experiências nas quais a integração entre profissionais comprometidos e os movimentos sociais têm permitido a emergência de práticas extremamente criativas e produtivas que são, inclusive, reconhecidas internacionalmente. A atuação de muitos profissionais e movimentos orientados pela Educação Popular tem avançado muito na desconstrução do autoritarismo dos doutores, do desprezo ao saber e à iniciativa dos doentes e familiares, da imposição de soluções técnicas para problemas sociais globais e da propaganda política embutida na forma como o modelo biomédico vem sendo implementado. No entanto, não basta alguns saberem fazer. É preciso que o saber seja difundido e generalizado 
nas instituições de saúde. Temos condições de superar a fase em que as práticas de saúde mais integradas à lógica de vida da população aconteciam apenas em experiências alternativas pontuais e transitórias. É preciso encontrar os caminhos administrativos e de formação profissional que permitam que elas se generalizem institucionalmente.

Várias iniciativas de governos municipais têm caminhado neste sentido. As experiências mais avançadas de incorporação da metodologia da Educação Popular como instrumento de reorientação da globalidade das políticas de saúde aconteceram nas administrações municipais das prefeituras de Recife (20002004) e Camaragibe (1996-2004), ambas em Pernambuco e administradas pelo Partido dos Trabalhadores, e no governo estadual de Miguel Arraes (19941998), também em Pernambuco. Em várias outras administrações municipais e estaduais, foram também implementadas iniciativas menos abrangentes de fortalecimento da participação popular nos vários serviços, com a metodologia da Educação Popular. A partir dessas experiências, há hoje um saber significativo sobre os caminhos administrativos e as estratégias políticas para utilização da Educação Popular como instrumento de gestão de políticas sociais.

Apesar de o princípio da participação comunitária ser amplamente aceito, há enormes resistências de setores progressistas do Movimento Sanitário, com a utilização da Educação Popular como instrumento de gestão das políticas de saúde. O processo de reforma sanitária ficou, nos últimos 20 anos, centrado, de um lado, nas respostas às questões postas pela construção do arcabouço jurídico e institucional do sistema e, por outro, no desejo de expandir rapidamente a cobertura dos serviços de saúde. Formou-se um amplo corpo técnico nas instâncias gestoras da burocracia federal, estadual, municipal e distrital, muito competente em atividades de planejamento e com grande habilidade no manejo do jogo de poder institucional, mas, via de regra, intolerante em processos participativos nos quais a população e os profissionais de nível local se manifestem de modo efetivo e autônomo. A lógica e o ritmo dos movimentos sociais e das pequenas práticas locais de enfrentamento dos problemas de saúde se chocam com a lógica e o ritmo de trabalho dos gestores do setor saúde, mesmo daqueles que se dizem progressistas. Eles concordam com a importância da participação popular, mas não sabem conviver com as surpreendentes formas como ela se manifesta fora dos espaços institucionais formais, os conselhos e as conferências de saúde, no embate político. 
A expansão do Programa Saúde da Família levou a uma profunda inserção de milhares de trabalhadores de saúde no cotidiano da dinâmica de adoecimento e de cura na vida social. Nessa convivência estreita, os profissionais de saúde são profundamente questionados sobre a eficácia do modelo biomédico tradicional. Há uma intensa busca de novos caminhos. Mas a pouca ênfase da saúde pública na discussão e no aperfeiçoamento das relações culturais e políticas com os cidadãos e seus movimentos vem resultando em desperdício dessa situação potencialmente transformadora do sistema. Os cursos de formação na academia e nas secretarias de Saúde pouco têm priorizado a discussão dos difíceis caminhos, cheios de armadilhas, da ação pedagógica voltada para a apuração do sentir, pensar e agir dos atores envolvidos nos problemas de saúde, de forma a se construir coletivamente as novas soluções sanitárias necessárias. Neste cenário, tem-se assistido, na maioria dos serviços, à reprodução de ações educativas extremamente normatizadoras e centradas apenas na inculcação de hábitos individuais considerados saudáveis. Esta forma de trabalho educativo boicota a participação popular, pois faz calar os sujeitos e afasta as lideranças locais do envolvimento, com os serviços, do processo de transformação social através do diálogo de saberes e da reflexão crítica de suas realidades de vida e saúde.

Quase todos os gestores enfatizam em seus discursos a importância da ação educativa e da promoção da saúde. No entanto, pouco se tem investido em uma política consistente que busque a difusão do saber da Educação Popular para a ampliação da participação popular no cotidiano dos serviços. Experiências municipais pioneiras, como de Camaragibe e Recife, têm demonstrado a importância do investimento, tanto na formação profissional, para a transformação cultural e política dos padrões das práticas de saúde, como também na criação de uma infra-estrutura institucional que garanta condições materiais e administrativas para a realização de atividades educativas.

Na falta do incentivo a ações educativas participativas em todo o sistema, o tradicional modelo autoritário e normativo de educação em saúde mantém-se dominante, em que pesem os discursos aparentemente progressistas. As coordenações de educação, comunicação e promoção da saúde das secretarias estaduais e municipais de Saúde, em vez de investir na reorientação da relação cultural que acontece em cada serviço de saúde, têm-se dedicado principalmente à organização de mobilizações da população para eventos e campanhas de massa ou no desenvolvimento de ações educativas isoladas, desconectadas da 
rotina da rede assistencial. Estão mais a serviço do marketing da instituição e de suas lideranças políticas.

A Rede de Educação Popular e Saúde tem proposto a adoção da Educação Popular como diretriz teórica e metodológica da política de educação em saúde do SUS. Essa política deveria se tornar uma estratégia prioritária de humanização do SUS e de adequação de suas práticas e técnicas à lógica de vida da população, por meio da valorização de formas participativas de relação entre os serviços de saúde e os usuários. Até agora, a Educação Popular em Saúde se expandiu no Brasil por um movimento de base em que os resultados de uma experiência atraem novos atores para tentativas semelhantes. Após 40 anos convivendo com esse movimento, sabe-se que ele não é suficiente para uma transformação mais generalizada da estrutura dos serviços de saúde. É preciso que esse movimento de base se some com transformações que partam também das instâncias de direção nacional, estadual e municipal da política de saúde. As quatro décadas de experiência com iniciativas de Educação Popular no campo da saúde permitiram também o acúmulo de um saber sobre diretrizes para a gestão das políticas de saúde capazes de ampliar as relações de troca cultural entre os serviços e a população.

Para isto, é necessário desencadear uma ação política que, bem estruturada, incentive, apóie e responsabilize os municípios e estados pela formulação de iniciativas amplas da valorização de criação de espaços de troca cultural, diálogo e negociação em cada serviço de saúde. Simpatias e discursos enobrecedores à educação e à promoção da saúde não podem substituir a destinação de recursos e implementação de políticas bem traçadas. É urgente a criação de uma política nacional de formação profissional em Educação Popular, de incentivo à produção descentralizada de materiais educativos construídos de forma participativa e de valorização e difusão das iniciativas educativas na lógica da problematização coletiva, já existentes em quase todos os municípios. É preciso que as campanhas educativas de massa passem a ser planejadas de forma articulada com os profissionais e lideranças dos movimentos sociais que vivem as dificuldades e potencialidades do trabalho educativo na rotina dos serviços de saúde.

Devido à forte presença da Educação Popular no Brasil, temos, em cada recanto da nação, profissionais de saúde e lideranças de movimentos sociais habilitados a colaborar nessa tarefa. É preciso mobilizá-los e valorizálos. Convocados, poderão colaborar na definição dos caminhos institucionais 
que tornem realmente efetiva a diretriz constitucional do SUS - a participação da comunidade - na redefinição do modelo assistencial.

A Educação Popular é um saber importante para a construção da participação popular, servindo não apenas para a criação de uma nova consciência sanitária, como também para uma democratização mais radical das políticas públicas. Não é apenas um estilo de comunicação e ensino, mas também um instrumento de gestão participativa de ação social. É também o jeito brasileiro de fazer promoção da saúde. É importante que deixe de ser uma prática social que acontece de forma pontual no sistema de saúde, por meio da luta heróica de alguns profissionais de saúde e de movimentos sociais, para ser generalizado amplamente nos diversos serviços de saúde, em cada recanto da nação. Uma das estratégias para isto é apoiar iniciativas de formação profissional que busquem reorientar as atitudes dos trabalhadores de saúde na relação com a população.

\section{Educação Popular na Formação dos Profissionais de Saúde}

Tem-se erroneamente associado o conceito de Educação Popular à educação informal dirigida ao público popular. O adjetivo "popular" presente no nome Educação Popular se refere não à característica de sua clientela, mas à perspectiva política dessa concepção de educação: a construção de uma sociedade em que as classes populares deixem de ser atores subalternos e explorados para serem sujeitos altivos e importantes na definição de suas diretrizes culturais, políticas e econômicas. A experiência dos movimentos sociais tem mostrado que esse modo de conduzir o processo educativo pode ser aplicado com sucesso na formação profissional. Muitas iniciativas educacionais nas universidades (principalmente em projetos de extensão), nos treinamentos das secretarias de Saúde de seus profissionais e nas organizações nãogovernamentais vêm sendo orientadas pela Educação Popular, descobrindo, aos poucos, os caminhos metodológicos de sua aplicação no novo contexto institucional. A educação dos trabalhadores de saúde nesta perspectiva é fundamental para a ampliação de uma gestão participativa no SUS.

A maioria dos atuais educadores populares se formou a partir de circunstâncias bastante particulares de sua vida pessoal que propiciaram contatos intensos com movimentos sociais e experiências de Educação Popular que os mobilizaram e os envolveram nesse tipo de prática. Desde a década de setenta, 
profissionais de saúde insatisfeitos com as práticas mercantilizadas e rotinizadas dos serviços oficiais e desejosos de uma atuação mais significativa para as classes populares vêm-se dirigindo às periferias dos grandes centros urbanos e regiões rurais, em busca de formas alternativas de atuação. Inicialmente ligaram-se às experiências informais de trabalho comunitário, principalmente junto à Igreja Católica. Posteriormente, a multiplicação de Serviços de Atenção Primária à Saúde ocorrida no Brasil, a partir do final dos anos setenta, colaborou na criação de condições institucionais para a inserção desses profissionais nos locais de moradia das classes populares.

É interessante como esse movimento de profissionais de saúde vem se mantendo por tantos anos. Convivendo com a dinâmica do processo de adoecimento e de cura no meio popular, interagindo com os movimentos sociais locais e entrando em contato com a militância de outros grupos intelectuais, muitos passam a reorientar suas práticas, buscando enfrentar de forma mais global os problemas de saúde encontrados. Mas as atuais exigências políticas e institucionais não permitem ficar apenas aguardando a formação espontânea e ocasional de profissionais abertos a iniciativas populares na construção de soluções sanitárias. É imensa a carência de profissionais capazes de uma relação participativa com a população e seus movimentos. Ao mesmo tempo, a eleição de governos comprometidos com os movimentos sociais em alguns municípios e estados e a eleição de Lula para Presidente da República criaram condições institucionais para uma maior incorporação da Educação Popular nas várias instâncias de formação profissional.

Hoje, um dos maiores desafios do movimento da Educação Popular em Saúde é o delineamento mais preciso das estratégias educativas de sua incorporação ampliada nos cursos de graduação de todos os profissionais de saúde, na formação de agentes comunitários de saúde, na educação permanente dos trabalhadores do SUS, nos cursos de pós-graduação etc. Por muito tempo, os educadores populares tiveram preconceito contra os doutores do setor saúde, vistos como opressores. Mas uma aproximação mais atenta dos profissionais de saúde tem mostrado como sua realidade de trabalho é marcada também por angústias e injustiças. Empresários e dirigentes políticos, preocupados com os ganhos eleitorais e financeiros, cobram dos trabalhadores de saúde - situados em serviços precários, recebendo salários aviltantes, marcados pelo clientelismo político e por uma gestão autoritária - a solução de complexos problemas da sociedade. Numa imagem figurada, pode-se dizer que os profissionais de saúde funcionam como pára-choques no embate entre a população carregada de 
problemas graves de saúde e exigências, de um lado, e, de outro, as instituições de saúde esvaziadas pela crise fiscal do Estado e o descaso político. Do mesmo modo que a Educação Popular nos movimentos sociais deve partir das situações de opressão e angústia ali vividas, a Educação Popular dos doutores pode fazer o mesmo. No campo da saúde também há grande diversidade de movimentos sociais, importantes aliados nos processos educativos.

Uma atitude reflexiva e crítica diante da sociedade, a compaixão com o sofrimento humano, a sensibilidade com a sutileza das manifestações das dinâmicas subjetivas e o engajamento com os movimentos sociais não podem ser ensinados maciçamente através de disciplinas teóricas. Mas se podem criar situações pedagógicas, orientadas pela experiência acumulada da Educação Popular, em que são problematizadas as vivências e indignações dos profissionais em sua relação com a realidade, compartilhadas iniciativas de enfrentamento e busca de soluções e valorizada a curiosidade na busca de entendimento das raízes das questões sociais mais importantes.

No ensino profissional em saúde brasileiro, nos últimos anos, tem-se divulgado muito a abordagem educacional denominada "Aprendizagem Baseada em Problemas" (PBL - Problem-Based Learning), a partir de experiências realizadas inicialmente no Canadá, EUA e Holanda. Ela tem ajudado a criar alternativas ao modelo de ensino em saúde tradicional, baseado em disciplinas especializadas e estanques, que fragmentam a análise dos problemas de saúde, procurando substituí-las pelo estudo de problemas concretos de forma interdisciplinar e cooperativa. A experiência acumulada pela Educação Popular', em caracterizar os problemas a serem debatidos, articulá-los com a realidade social e encaminhar as soluções parciais num processo contínuo de ação e reflexão pode ser importante para que o Aprendizado Baseado em Problemas na América Latina assuma características transformadoras mais radicais que apontem para uma prática sanitária capaz de romper com as práticas técnicas individuais restritas a ações medicamentosas, tentativas de mudanças de comportamentos de risco e medidas de saneamento tradicionais. Uma prática sanitária integrada a uma ação coletiva e solidária voltada a superar as raízes políticas, culturais e econômicas do sofrimento humano. 


\section{Referências}

BRANDÃO, C. R. Lutar com a palavra: escritos sobre o trabalho do educador. Rio de Janeiro: Graal, 1982.

REDE DE EDUCAÇÃO POPULAR E SAÚDE. Carta: a Educação Popular em saúde e o governo popular e democrático do Partido dos Trabalhadores. Nós da Rede - Boletim da Rede de Educação Popular e Saúde. Recife, n. 3, p. 6-8, 2003.

VASCONCELOS, E. M. Educação Popular nos serviços de saúde. São Paulo: Hucitec, 1997.

\section{NOTAS}

1 Professor do Departamento de Promoção da Saúde da Universidade Federal da Paraíba. Aluno do Curso de Pós-doutorado da Escola Nacional de Saúde Pública da Fundação Oswaldo Cruz (ENSP/ FIOCRUZ), no Rio de Janeiro.

2 Para contato, acesse os portais da Internet < http://br.groups.yahoo.com/group/edpopsaude_> ou < http://www.redepopsaude.com.br_>, ou entre em contato com a sua Secretaria Executiva, na Av. Brasil 4.036, sala 905, Rio de Janeiro, CEP. 21040-360, telefone (+21) 2260-7453.

3 Paulo Freire, muitas vezes, a ela se referia como pedagogia da problematização. 
Popular Education: from an alternative practice to a strategy for participatory health policy management

Many health professionals in Brazil have been drawn to the popular education movement and the struggle by grassroots social movements to change the country's health care system. As a result, numerous health services in the country have incorporated participatory relations with the community that break with the prevailing authoritarian tradition. Such relations have helped deconstruct: medical authoritarianism, the disregard for patient and family knowledge and initiatives, imposition of technical solutions to broader social problems, and political propaganda embedded in the implementation of the biomedical model. However, it does not suffice for only few to adopt such an approach. It is necessary to disseminate such knowledge in health institutions as a whole. The increasing strength of the Brazilian social movement is creating the institutional conditions to move beyond a previous phase in which health practices integrated with the logic of the population's reality occurred in only a limited number of transient alternative experiences. It is necessary to find administrative channels and professional training to foster the widespread adoption of such approaches within the Unified National Health System (SUS).

Key words: Popular education; social movement; health practices.

Recebido em: 10/05/2004.

Aprovado em: 28/05/2004. 